\title{
Impact of Sulphate Counter Ion in the Migration of Sodium Ion through Soils
}

\author{
Puvvadi Venkata Sivapullaiah ${ }^{1}$, Maya Nayak ${ }^{2}$, Ponnapureddy Hari Prasad Reddy ${ }^{3}$, Jangam Sumalatha ${ }^{4}$ \\ ${ }^{1}$ Indian Institute of Science, Bangalore, India; ${ }^{2}$ B. M. Sreenivasaish College of Engineering, Bangalore, India; ${ }^{3}$ National Institute of \\ Technology, Warangal, India; ${ }^{4}$ M. S. Ramaiah Institute of Technology, Bangalore, India. \\ Email: siva@civil.iisc.ernet.in
}

Received February 22 ${ }^{\text {nd }}, 2010$; revised April 30 ${ }^{\text {th }}, 2010$; accepted May $3^{\text {rd }}, 2010$.

\begin{abstract}
Laboratory advection-diffusion tests are performed on two regional soils-Brown Earth and Red Earth-in order to assess their capacity to control contaminant migration with synthetic contaminant solution of sodium sulphate with sodium concentration of $1000 \mathrm{mg} / \mathrm{L}$. The test was designed to study the transport/attenuation behaviour of sodium in the presence of sulphate. Effective diffusion coefficient $\left(D_{e}\right)$ that takes into consideration of attenuation processes is used. Cation exchange capacity is an important factor for the attenuation of cationic species. Monovalent sodium ion cannot usually replace other cations and the retention of sodium ion is very little. This is particularly true when chloride is anion is solution. However, sulphate is likely to play a role in the attenuation of sodium. Cation exchange capacity and type of exchangeable ions of soils are likely to play an important role. The effect of sulphate ions on the effective diffusion coefficient of sodium, in two different types of soils, of different cation exchange capacity has been studied. The effective diffusion coefficients of sodium ion for both the soils were calculated using Ogata Bank's equation. It was shown that effective diffusion coefficient of sodium in the presence of sulphate is lower for Brown Earth than for Red Earth due to exchange of sodium with calcium ions from the exchangeable complex of clay. The soil with the higher cation exchange retained more sodium. Consequently, the breakthrough times and the number of pore volumes of sodium ion increase with the cation exchange capacity of soil.
\end{abstract}

Keywords: Cation Exchange Capacity, Clays, Effective Diffusion Coefficient, Hydraulic Conductivity, Porous Media, Sodium, Sulphate

\section{Introduction}

Natural clay deposits and compacted clay liners can act as barriers for contaminant migration and limit contamination of ground water resources. Available mathematical models can be used to estimate the potential rates of migration of ions in soils, based on which the thickness of liners is designed considering the type of contaminants, local hydrology and nature of barrier material. This study describes results of laboratory column tests performed on two local soils to understand the processes controlling the migration of sodium ion and to assess their potential for liner application. Sodium ion is relatively least retarded of all cations. The retardation of other cations will be more and hence is possible to design thickness of liners based on studies conducted on sodium ions. Generally the retardation of sodium is least in presence of chloride ions. The effect of other ions such as sulphate on the retardation of sodium is not established. Based on the out come of the results it may be possible to economically design the thickness of liner to contain leachates where similar conditions exist. Transport of ions in porous media is controlled by a variety of physical, chemical and biological processes [1,2]. The physical processes include diffusion, advection and dispersion. The chemical processes include sorption, dissolution/precipitation, complexation, hydrolysis/substitution and oxidation.

When dealing with transport through aquifers the key transport mechanisms are usually advection and dispersion. The factors primarily affecting transport of species through porous media are hydraulic conductivity, k, dispersion coefficient $\mathrm{D}$, and the retardation factor, $\mathrm{R}$. The hydraulic conductivity affects the seepage velocity $\left(\mathrm{v}_{\mathrm{s}}\right)$, which causes advection flow driven by hydraulic gradient. Dispersion is the mixing process that causes the concentration front of species to spread out. Dispersion has two components: mechanical dispersion due to seepage velocity and diffusion due to concentration gradient. For low permeable soils such as clays, the advection component of dispersion, also called mechanical dispersion, is negligi- 
ble [3]. Therefore, for all practical purposes, dispersion, D, is equal to $D_{m}$ [4]. Thus diffusion is of major significance in the solute transport in porous fine-grained soils. Same is the case in any soils in which the velocity of fluid is low. Advection-dispersion flow occurs when seepage velocity is small and diffusion coefficient becomes an important factor.

The molecular diffusion coefficient is a fundamental property of the solute and the solvent (water). Molecular diffusion coefficients are tabulated for many chemicals in water. The rate of diffusion is sensitive to a number of parameters. Maximum rates of migration by diffusion occur in bulk or free water at extreme dilution. Free solution diffusion coefficient $\left(\mathrm{D}_{0}\right)$ would normally represent these maximum values. The rate of chemical movement or mass flux through a soil may be slower than by diffusion in pure water. Diffusion through a network of clay particles involves the diffusive movement of the species of interest in the pore water between clay particles. The tortuosity factor accounts for the increased distance of transport and the more tortuous pathways experienced by solutes diffusing through porous media, the lower is the tortuosity factor. Porous media diffusion coefficient $\left(D_{p}\right)$ takes into consideration of tortuosity factor $[5,6]$. The porous system diffusion coefficient $\mathrm{D}_{\mathrm{p}}$ can be calculated from Fick's law by

$$
\mathrm{D}_{\mathrm{p}}=\mathrm{D}_{0} \mathrm{~W}_{\mathrm{T}}=\theta \mathrm{D}_{\mathrm{e}}
$$

where $\mathrm{W}_{\mathrm{T}}$ is complex tortuosity factor, $\mathrm{D}_{0}$ is free solution diffusion coefficient; $\theta$ is volumetric water content;.

$$
\begin{gathered}
\mathrm{W}_{\mathrm{T}}=\alpha_{\mathrm{ff}} \gamma_{\mathrm{e}}\left(\mathrm{L} / \mathrm{L}_{\mathrm{e}}\right)^{2} \mathrm{D}_{0}=\tau \mathrm{D}_{0} \\
\tau=\alpha_{\mathrm{ff}} \gamma_{\mathrm{e}}\left(\mathrm{L} / \mathrm{L}_{\mathrm{e}}\right)^{2}
\end{gathered}
$$

where $\alpha_{\mathrm{ff}}$ is the decreased fluidity factor related to adsorbed double layer factor; $\gamma_{\mathrm{e}}$ is the electrostatic interaction factor; $\left(\mathrm{L} / \mathrm{L}_{\mathrm{e}}\right)^{2}$ is the geometric tortuosity factor and $\tau$ is the tortuosity factor for the clay. In saturated soils, the diffusion coefficient is even less than porous media diffusion coefficient, $D_{p}$, due to attenuation processes. The diffusion coefficient, which takes into account the various attenuation processes, is called effective diffusion coefficient, $\mathrm{D}_{\mathrm{e}}$.

\subsection{Effect of Attenuation Processes on Diffusion Coefficients}

The transport of ions through the soils may be retarded through the processes of sorption, precipitation, biodegradation, and filtration. The attenuation processes included are: cation removal, anion removal, and biodegradation. The important process for sorption of cations is by ion exchange at exchange sites and in the inter-layers of clays.

Other attenuation processes influence the effective diffusion coefficient $\left(D_{e}\right)$. However, the difference between porous media diffusion coefficient and effective diffusion coefficient is very little for conservative ions like chloride. Determination of diffusion coefficients of some common ions is important in estimating the total breakthrough times. Column tests are usually employed [7] to determine the diffusion coefficients. Diffusion coefficients are determined from the breakthrough curves plotted using column test data.

Generally sodium ion is retarded very little because normally sodium cannot replace other exchangeable ions of soil and adsorbed on to the clay surface. Barone et al. [8] have shown that the adsorption of sodium and potassium is affected by other exchangeable ions in the leachate. Anion plays an important role in this adsorption. It is proposed to study the retention of sodium in the presence of sulphate in soils of different cation exchange capacity. It is important to determine the effective diffusion coefficient $\left(D_{e}\right)$ of sodium in soils to model its migration through them using advection-dispersion equation. It is proposed to determine the diffusion coefficient of sodium for soils in the presence of sulphate ions.

\section{Materials}

\subsection{Brown Earth}

Brown earth obtained from a construction site on Airport road in Bangalore was used in this study. The sample was collected by open excavation from a depth of 1 meter from natural ground. The soil was dried and passed through IS 425-micron sieve. The soil belongs to $\mathrm{CH}$ as per unified soil classification.

\subsection{Red Earth}

Red earth used in this study was obtained from Indian Institute of Science Campus, Bangalore. The soil was collected by open excavation from a depth of 1 meter from natural ground. The soil was dried and passed through IS 425-micron sieve. The properties of both the soils used are determined as ASTM standards and presented in Table $\mathbf{1 .}$

\section{Experimental Procedures for Soil Column Test}

The apparatus used in this study was designed such that both diffusion and advective-diffusion tests could be performed (Figure 1).

The experimental set up consists of following four major components namely: Influent Reservoir, Pressure System, Column Assembly and Effluent Collector.

\subsection{Preparation of Sodium Sulphate Solution}

About 3.086 grams of $\mathrm{Na}_{2} \mathrm{SO}_{4}$ was weighed accurately and dissolved in water and made upto one litre in volumetric flask. The solution prepared for the study contained about 1000 ppm of sodium and 2088 ppm of sulphate. 
Table 1. Index and physico chemical properties of soils used

\begin{tabular}{ccc}
\hline Property & $\begin{array}{c}\text { Brown } \\
\text { Earth }\end{array}$ & Red Earth \\
\hline Specific gravity & 2.63 & 2.64 \\
Liquid Limit \% & 67.5 & 38.0 \\
Plastic Limit \% & 23.2 & 21.0 \\
$\quad \begin{array}{l}\text { Shrinkage Limit \% } \\
\text { Max Dry Density, g/cm }{ }^{3}\end{array}$ & 13.4 & 18.0 \\
$\begin{array}{c}\text { Optimum Moisture Content \% } \\
\text { Cation Exchange capacity, } \\
\text { (meq/100g) }\end{array}$ & 27.5 & 1.63 \\
Unified soil Classification Symbol & CH & 18.2 \\
\hline
\end{tabular}

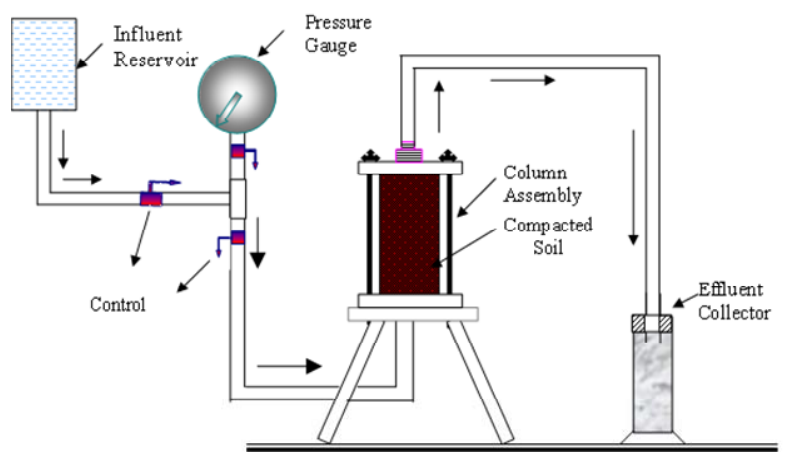

Figure 1. Experimental set up for soil column test

\subsection{Sample Preparation and Placement in the Column}

The oven dried soils of Red Earth and Brown Earth of required quantity was mixed with necessary amount of water separately as to prepare sample of required density. The soils were mixed thoroughly and kept in polythene bag in a humid desiccator overnight to achieve uniform moisture content. The soil was then compacted to the required density by dividing the soil into 3 equal parts by weight and then, each part is compacted into the (specimen) Plexiglass cylinder, one by one using a screw jack to ensure uniform compaction for the entire specimen in the column of Plexiglas cylinder of $32 \mathrm{~cm}$ long, $9.2 \mathrm{~cm}$ inner diameter and $0.5 \mathrm{~cm}$ thick. The dry density of soil was 0.85 times of Proctor's maximum dry density at water content $2 \%$ lower than optimum water content.

\subsection{Influent Reservoir}

The Influent Reservoir consists of a tank made of glass or polyethylene with two opening. One is at the top for transferring the synthetic source solution of interest into it and the other is at the bottom to allow it to migrate through the soil specimen. The solution is placed in the reservoir and stirred at frequent intervals so as to maintain constant initial concentration. The solution is then passed through the soil compacted in the column at high constant hydraulic gradient to reduce the testing duration to reasonable period. Pressure gauge is connected to the influent reservoir and to the column assembly. A uniform pressure of $15 \mathrm{kPa}$ is maintained throughout the ex-perimental period by controlling the flow rate from the influent reservoir.

\subsection{Relative Concentration of Sodium Ion in the Effluent}

The Effluent is collected in the effluent collector consisting of a measuring jar covered at the top so as to avoid evaporation of collected leachate. The volume of the effluent that comes out of the column with time was monitored at regular intervals and the concentration of sodium ion is measured. Knowing the initial and concentration of sodium after different intervals, relative concentration $\left(\mathrm{C} / \mathrm{C}_{0}\right)$ of sodium is calculated and the breakthrough curves are plotted.

\section{Determination of Effective Diffusion Coeffiecients}

Simple solutions to Ogata Bank's equation allowed determination of the diffusion coefficient using experimental results. In order to obtain the values of effective diffusion coefficients, a plot of relative concentration versus time or number of pore volumes are plotted. From the plot the time $\left(\mathrm{t}_{0.16}\right)$ corresponding to $\mathrm{C} / \mathrm{C}_{0}=0.16$ and time $\left(\mathrm{t}_{0.84}\right)$ corresponding to $\mathrm{C} / \mathrm{C}_{0}=0.84$ are obtained.

$$
\frac{\mathrm{C}}{\mathrm{C}_{0}}=\frac{1}{2}\left[\operatorname{erfc}\left(\frac{1-\mathrm{U}}{2 \sqrt{\mathrm{UDe} / \mathrm{vL}}}\right)\right]
$$

Using these values and knowing the thickness of liner (L) and knowing the value of velocity, effective diffusion coefficient is calculated using the following Ogata Bank's equation:

$$
\begin{gathered}
\mathrm{U}=\mathrm{vnAt} / \mathrm{ALn}=\mathrm{vt} / \mathrm{L} \\
\mathrm{J}_{0.84}=\left[(\mathrm{U}-1) / \mathrm{U}^{1 / 2}\right], \text { when } \mathrm{C} / \mathrm{C}_{0}=0.84 \\
\mathrm{~J}_{0.16}=\left[(\mathrm{U}-1) / \mathrm{U}^{1 / 2}\right] \text {, when } \mathrm{C} / \mathrm{C}_{0}=0.16
\end{gathered}
$$

From which $\mathrm{D}_{\mathrm{e}}=\mathrm{vL} / 8\left[\mathrm{~J}_{0.84}-\mathrm{J}_{0.16}\right]^{2}$

In addition to the above modified Ogata Bank's equation another expression for calculating the effective diffusion co-efficient of ionic species of interest are given [9] as follows:

$$
\mathrm{De}_{\mathrm{e}}=\frac{1}{8}\left[\frac{\mathrm{x}-\mathrm{vt}_{0.16}}{\sqrt{\mathrm{t}_{0.16}}}-\frac{\mathrm{x}-\mathrm{vt}_{0.84}}{\sqrt{\mathrm{t}_{0.84}}}\right]^{2}
$$


where $\mathrm{t}_{0.16}=$ time at $\mathrm{C} / \mathrm{C}_{0}=0.16$;

$$
\mathrm{t}_{0.84}=\text { time at } \mathrm{C} / \mathrm{C}_{0}=0.84
$$

It was observed that the values of effective diffusion co-efficient obtained using both Ogata Bank's equation and Fried and Cambarnous equation were same.

\section{Results and Discussion}

The various aspects examined for Brown Earth and Red Earth are

1) Rate of flow of salt solution through the compacted soil column;

2) Variation of concentration of individual ions in the effluent with time;

3) Calculation of diffusion coefficient of ions;

4) Prediction of the breakthrough curves.

\subsection{Brown Earth}

Rate of flow of sodium sulphate solution through soil column:

Brown earth is compacted into the column assembly and initially saturated with distilled water. Then the sodium sulphate solution containing $1000 \mathrm{ppm}$ of sodium is passed through the soil column under a pressure of $15 \mathrm{kPa}$. The rate of flow of the leachate through the soil column is monitored.

While carrying out column experiments it is necessary to monitor the rate of flow of influent fluid through soil column. For this the volume of leachate (or effluent) collected for different periods is measured. Using this data variation of rate of flow with time is plotted as shown in Figure 2. From the graph it can be observed that the variation of rate of flow is almost constant with an average rate of flow being $3.78 \times 10^{-4} \mathrm{~cm}^{3} / \mathrm{s}$. This amounts to an average permeability of about $1.1 \times 10^{-6} \mathrm{~cm} / \mathrm{s}$.

It can be seen from Figure 3 that the cumulative volume increases linearly upto about 480 hours with the cumulative rate of leachate flow being about $8.26 \times 10^{-4}$ $\mathrm{cm}^{3} / \mathrm{s}$. With further increase in time leachate flow rate reduces with an average cumulative flow rate being $4.35 \times$

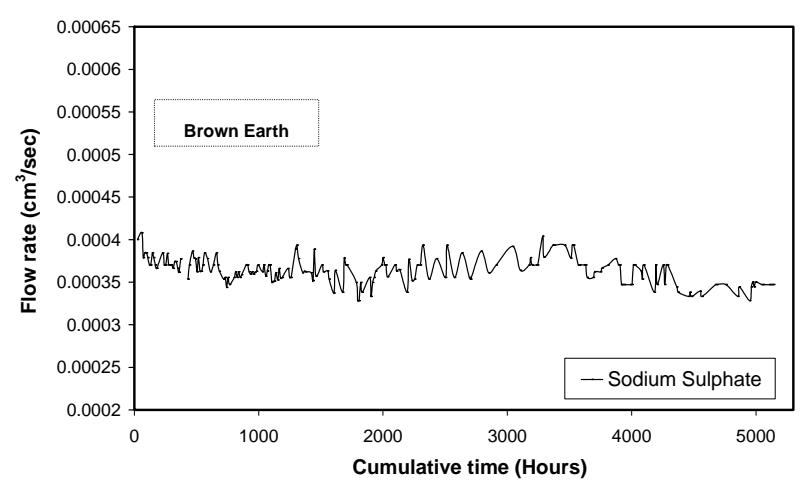

Figure 2. Variation of flow rate of sodium sulphate solution with time in Brown Earth
$10^{-4} \mathrm{~cm}^{3} / \mathrm{s}$ and hence velocity also reduces. This decrease in velocity may be due to precipitation of salts formed by reaction between leachate and the soil. Probably $\mathrm{Ca}^{2+}$ ions present on the surface of clay particles as exchangeable ions reacts with sulphate to form $\mathrm{Ca}_{2} \mathrm{SO}_{4}$.

$$
\mathrm{Ca}^{2+} \mathrm{Clay}+\mathrm{Na}_{2} \mathrm{SO}_{4} \rightarrow \mathrm{Ca}_{2} \mathrm{SO}_{4}+\mathrm{Na}^{+} \text {Clay }
$$

Normally $\mathrm{Na}^{+}$ions cannot replace exchangeable $\mathrm{Ca}^{2+}$ from clay exchangeable ion complex. But because of precipitation of $\mathrm{Ca}_{2} \mathrm{SO}_{4}$, Calcium ions are removed from ion complex and $\mathrm{Na}^{+}$ions get into exchangeable ion complex. With increase in time all the exchangeable $\mathrm{Ca}^{2+}$ are precipitated as $\mathrm{Ca}_{2} \mathrm{SO}_{4}$. No more precipitation occurs after the complete removal of available calcium and the rate of flow through the soil remains constant. Then the seepage velocity remains fairly constant for long time. This constant velocity is about $5.46 \times 10^{-6} \mathrm{~cm} / \mathrm{s}$.

Variation of concentration of sodium ion with cumulative time.

The effective diffusion coefficients of ions in both the soils were determined from the curve of variation of concentration with time using the Ogata Bank's equation. The detailed calculations are shown in Table 2.

Figure 4 shows the variation of relative concentration of sodium ion with cumulative time, which represents the breakthrough curve of sodium. From the graph it can be seen that, the curve is S-Shaped and the relative concentration increasing gradually with time. $50 \%$ of the initial concentration (i.e., $\mathrm{C} / \mathrm{C}_{0}=0.5$ ) of $\mathrm{Na}^{+}$is reached at 2210 hours and $100 \%$ of initial concentration (i.e., $\mathrm{C} / \mathrm{C}_{0}=1$ ) after 4854 hours.

From the curve the value of $t_{0.16}$ (time corresponding to $\mathrm{C} / \mathrm{C}_{0}=0.16$ ) and $\mathrm{t}_{0.84}$ (time corresponding to $\mathrm{C} / \mathrm{C}_{0}=0.84$ ) are obtained which are used in calculating the diffusion co-efficient of $\mathrm{Na}^{+}$ion. The diffusion co-efficient of $\mathrm{Na}^{+}$ion as calculated is $2.771 \times 10^{-6}$. Also the total time taken for the leachate to reach $\mathrm{C} / \mathrm{C}_{0}=1$ is obtained which is useful in designing the thickness of liner.

\subsection{Red Earth}

Rate of flow of sodium sulphate solution through Red Earth soil column.

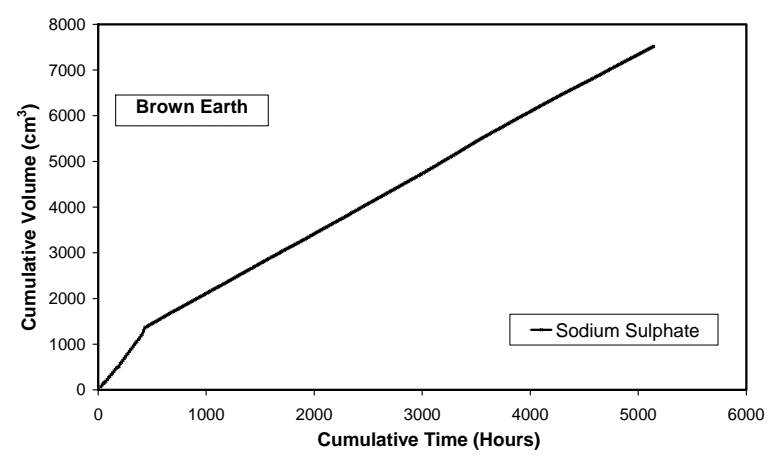

Figure 3. Variation of cumulative volume with time for Brown Earth 
Table 2. Calculation of effective diffusion coefficient of sodium ions in soils

\begin{tabular}{|c|c|c|c|}
\hline \multirow{2}{*}{$\begin{array}{l}\text { Sl. } \\
\text { No. }\end{array}$} & \multirow{2}{*}{ Parameters } & \multicolumn{2}{|c|}{ Soil Type } \\
\hline & & Brown Earth & Red Earth \\
\hline 1 & $\begin{array}{l}\text { Hydraulic conductiv- } \\
\text { ity, } \mathrm{k}, \mathrm{cm} / \mathrm{sec}\end{array}$ & $1.10 \mathrm{E}-06$ & 2.99E-06 \\
\hline 2 & $\begin{array}{c}\text { Darcy velocity, V, } \\
\text { cm/sec }\end{array}$ & $5.49 \mathrm{E}-06$ & $1.50 \mathrm{E}-05$ \\
\hline 3 & $\mathrm{t}_{0.16}$ in hours & 2110 & 587 \\
\hline 4 & $\mathrm{t}_{0.84}$ in hours & 3009 & 772 \\
\hline 5 & $\mathrm{U}_{0.16}=\frac{v t_{0.16}}{L}$ & 1.390 & 1.055 \\
\hline 6 & $\mathrm{U}_{0.84}=\frac{v t_{0.84}}{L}$ & 1.982 & 1.388 \\
\hline 7 & $\mathrm{vL} / 8$ & 2.059E-05 & $5.618 \mathrm{E}-05$ \\
\hline 8 & $\mathrm{U}_{0.16}-1$ & 0.3901 & -0.055 \\
\hline 9 & $\mathrm{U}_{0.84}-1$ & 0.982 & 0.388 \\
\hline 10 & $\sqrt{ } \mathrm{U}_{0.16}$ & 1.17901 & 0.762 \\
\hline 11 & $\sqrt{\mathrm{U}_{0.84}}$ & 1.408 & 1.273 \\
\hline 12 & $\mathrm{~J}_{0.16}=\frac{\mathrm{U}_{0.16}-1}{\sqrt{\mathrm{U}_{0.16}}}$ & 0.331 & -0.072 \\
\hline 13 & $J_{0.84}=\frac{U_{0.84}-1}{\sqrt{U_{0.84}}}$ & 0.698 & 0.305 \\
\hline 14 & {$\left[\mathrm{~J}_{0.84}-\mathrm{J}_{0.16}\right]$} & -0.367 & -0.377 \\
\hline 15 & {$\left[\mathrm{~J}_{0.84}-\mathrm{J}_{0.16}\right]^{2}$} & 0.135 & 0.143 \\
\hline 16 & $\begin{array}{c}\mathrm{D}_{\mathrm{e}}=\mathrm{vL} / 8 *\left[\mathrm{~J}_{0.84}-\mathrm{J}_{0.16}\right]^{2} \\
\mathrm{~cm}^{2} / \mathrm{sec}\end{array}$ & $2.770 \mathrm{E}-06$ & 7.995E-06 \\
\hline 17 & $\mathrm{D}_{0} \mathrm{~cm}^{2} / \mathrm{sec}$ & 1.33E-05 & 1.33E-05 \\
\hline 18 & $\tau=\mathrm{D}_{\mathrm{e}} / \mathrm{D}_{0}$ & 0.208 & 0.601 \\
\hline
\end{tabular}

As explained earlier the Red Earth soil sample is compacted in 3 equal layers to 0.85 times dry density and dry of optimum by $2 \%$ and initially saturated with distilled water. Then the influent sodium sulphate solution containing $1000 \mathrm{ppm}$ of sodium and $2088 \mathrm{ppm}$ of sulphate is passed through the Red Earth soil column under a constant pressure of $15 \mathrm{kPa}$, and the volume of effluent flow through the Red Earth soil column is monitored.

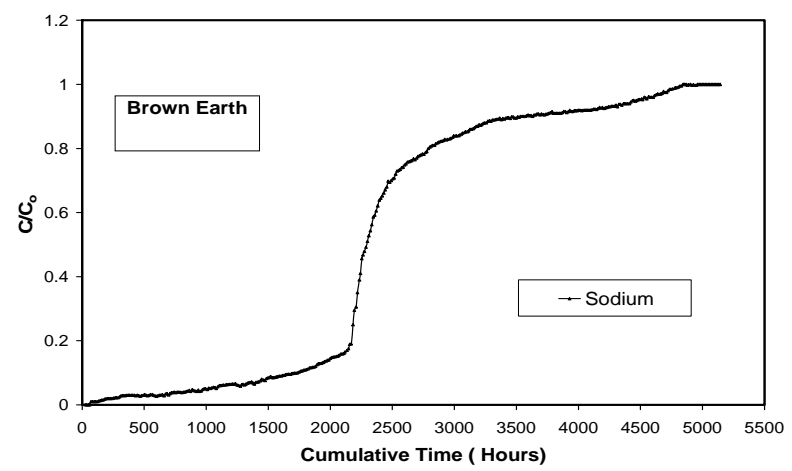

Figure 4. Variation of relative concentration of sodium with time for brown earth

Figure 5 shows the variation of rate of flow of sodium sulphate through column. It can be seen from the graph that the rate of flow is almost constant throughout the experiment with an average flow rate of $1.052 \times 10^{-3} \mathrm{~cm}^{3} / \mathrm{s}$. Thus the permeability of Red Earth to leachate is about $2.99 \times 10^{-6} \mathrm{~cm} / \mathrm{s}$.

Figure 6 shows the variation of cumulative volume of leachate with cumulative time. From the graph it can be observed that the cumulative volume increases almost linearly with time without much change. Hence the cumulative rate of flow of leachate remains almost constant at about $1.25 \times 10^{-3} \mathrm{~cm}^{3} / \mathrm{s}$. Also the velocity also remains constant and is found to be about $1.50 \times 10^{-5} \mathrm{~cm} / \mathrm{s}$. However this velocity is more compared to that of Brown Earth, which is attributed to the fact that velocity of a fluid in soil mainly depends on its porosity.

Even though porosities of Brown Earth and Red Earth are nearly same seepage velocity is more in Red Earth than in Brown Earth. This is because the amount of absorbed water present in voids is different for different soils. The higher the CEC, higher would be adsorbed water. Thus, in Red Earth amount of adsorbed waters with CEC of $18.5 \mathrm{meq} / 100 \mathrm{~g}$ is less than that of Brown Earth with CEC of $30.77 \mathrm{meq} / 100 \mathrm{~g}$.

Variation of concentration of sodium ion with cumulative time.

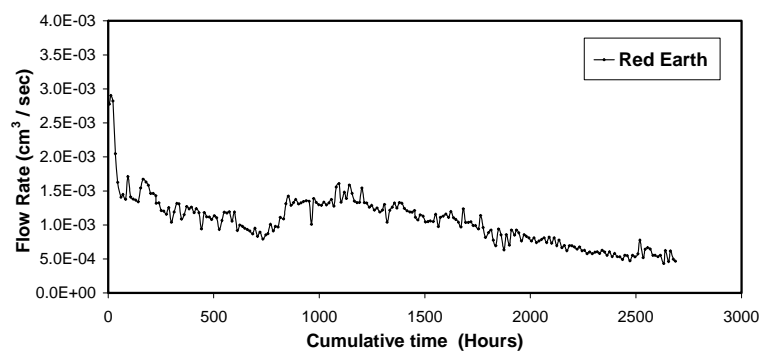

Figure 5. Variation of flow rate of sodium sulphate with time in Red Earth 


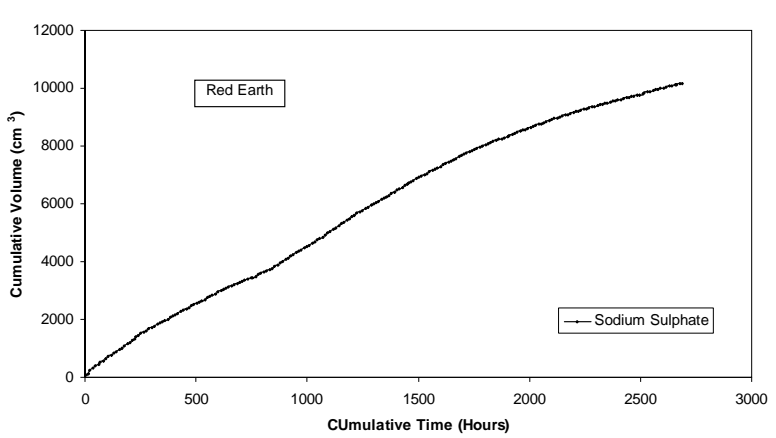

Figure 6. Variation of cumulative volume with time for Red Earth

Figure 7 shows the variation of relative concentration of sodium with cumulative time for Red Earth soil sample. From the graph it can be observed that the curve is $\mathrm{S}$-Shaped and the relative concentration increasing gradually with time. $50 \%$ of the initial concentration (i.e., $\mathrm{C} / \mathrm{C}_{0}=0.5$ ) of $\mathrm{Na}^{+}$reaches at 696 hours and $100 \%$ of initial concentration (i.e., $\mathrm{C} / \mathrm{C}_{0}=1$ ) after 2113 hours. From the curve the value of $t_{0.16}$ (time corresponding to $\mathrm{C} / \mathrm{C}_{0}=0.16$ ) and $\mathrm{t}_{0.84}$ (time corresponding to $\mathrm{C} / \mathrm{C}_{0}=0.84$ ) are obtained which are used in calculating the diffusion co-efficient of $\mathrm{Na}^{+}$ion. The diffusion co-efficient of $\mathrm{Na}^{+}$ ion as calculated is $8.0 \mathrm{E}-06$. Also the total time taken for the leachate to stabilize, i.e., to reach $\mathrm{C} / \mathrm{C}_{0}=1$ is obtained which is useful in designing the thickness of liner.

\subsection{Comparison of Variation of Concentration of Sodium Ion in Brown Earth and Red Earth}

From Figure 8, it can be observed that the number of pore volumes of flow for sodium ion to reach $\mathrm{C} / \mathrm{C}_{0}=0.5$ occurs at 5 pore volume for Brown Earth and 4.15 pore volume for Red Earth. Thus the breakthrough of sodium at $\mathrm{C} / \mathrm{C}_{0}=$ 0.5 is higher for Brown Earth than that of Red Earth. This is a consequence of mechanism of retention of sodium in soils, which is explained as follows.

Sodium ion, considered as classical conservative ion, gets retarded in two soils studied to varying extents in the presence of sulphate.

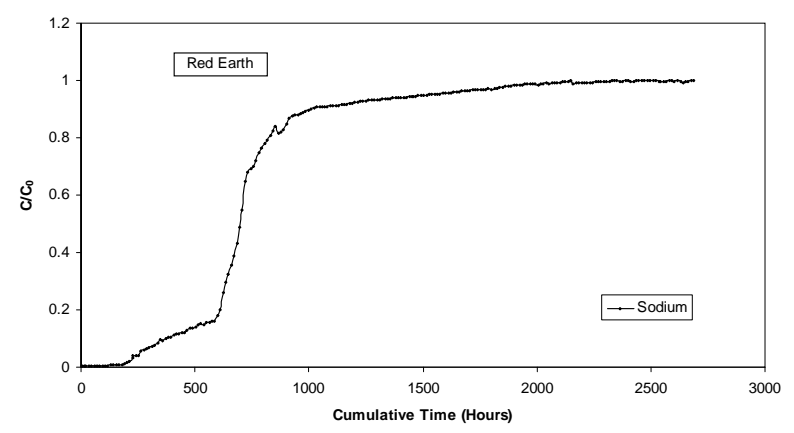

Figure 7. Variation of relative concentration of sodium with time for Red Earth

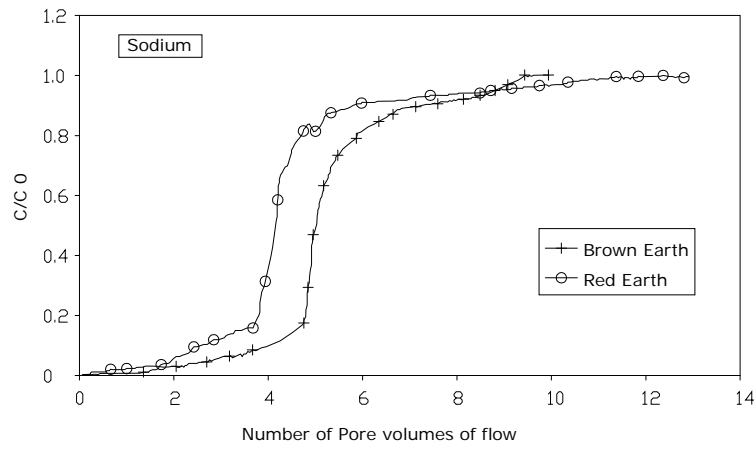

Figure 8. Variation of relative concentration of sodium with time for Brown Earth and Red Earth

The retardation of sodium is due to retention of sodium in place of exchangeable calcium. Calcium cannot normally be replaced by sodium. But in the presence of sulphate ion, calcium can form insoluble salt and is removed from ion complex of the clay. Then sodium occupies the exchangeable position and is retained. The higher the cation exchange capacity of the soil with respect to calcium the higher should be the retention.

\subsection{Effect of Sulphate Ion on Theoretical Break through Curves of Sodium in Brown Earth and Red Earth}

Using the experimental determined effective diffusion coefficient and knowing the field hydraulic data simulations were conducted with available mathematical models using Matlab v6 to predict breakthrough curves of sodium ion for the soils.

Breakthrough curves of sodium ion in soils are obtained using Ogata Bank’s Equation (10) for advection-dispersion process.

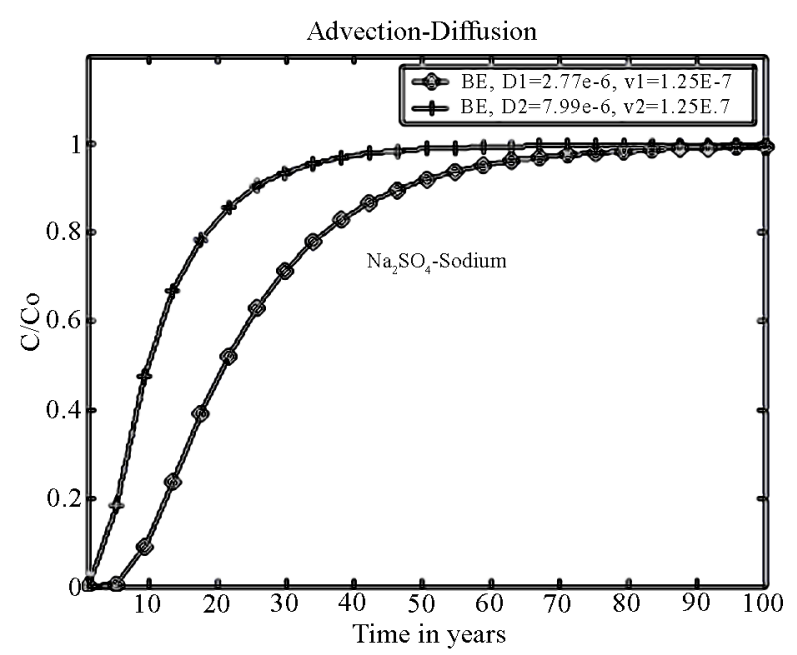

Figure 9. Breakthrough curves for sodium ion in Brown Earth and Red Earth 


$$
\frac{\mathrm{C}}{\mathrm{C}_{0}}=\frac{1}{2}\left[\operatorname{erfc}\left(\frac{\mathrm{Z}-\mathrm{Vst}}{2 \sqrt{(\mathrm{Det})}}\right)+\exp \left(\frac{\mathrm{Vs} Z}{\mathrm{De}_{\mathrm{e}}}\right) \operatorname{erfc}\left(\frac{\mathrm{Z}+\mathrm{vst}}{2 \sqrt{(\mathrm{Det})}}\right)\right]
$$

where, $\mathrm{C} / \mathrm{C}_{0}=$ ratio of effluent concentration to influent concentration

$D_{e}=$ Effective diffusion coefficient of contaminating species

$\mathrm{Z}=$ Thickness of the liner

$\mathrm{t}=$ Time

$\mathrm{v}_{\mathrm{s}}=$ Seepage velocity of pore fluid

Two types of compacted soils were considered in the simulation. The thickness of the clay layer used in the liner system was $1 \mathrm{~m}$. For obtaining $\mathrm{v}_{\mathrm{s}}$, the usual permeability of most in-situ soils of about $1.25 \times 10^{-7} \mathrm{~cm} / \mathrm{s}$ and porosity of about 0.4 is assumed. The hydraulic gradient of 1 is taken. The theoretical breakthrough curves of sodium obtained are presented in Figure 9. It can be observed that using the experimentally determined effective diffusion coefficient and assuming the same field conditions breakthrough of sodium ion in Brown Earth is about 24 years where as for Red Earth is about 11 years. Thus it can be concluded that sodium ion is taking considerably more time for breakthrough in Brown Earth than in Red Earth. Thus the effect of small variation in the effective diffusion coefficients is significant on breakthrough times.

\section{Conclusions}

1) The number of pore volumes required for breakthrough for sodium is higher for Brown Earth than Red Earth. Consequently the effective diffusion co-efficient of sodium is much lower for Brown Earth than Red Earth. Because of higher cation exchange capacity of Brown Earth sodium is retarded more in Brown Earth than in Red Earth.

2) The reason for the retardation of sodium by these soils is the exchange of sodium with calcium ions from the exchangeable complex of clay. The exchange is possible because of removal of calcium from the exchangeable complex to form calcium sulphate, sodium ions occupy exchangeable sites and are retarded.

3) At same field conditions small variation in the effective diffusion coefficient causes large variations in the breakthrough times for different type of soils.

\section{REFERENCES}

[1] R. A. Freeze and J. A. Cherry, "Groundwater," PrenticeHall, Inc., EngleWood Cliffs, 1979.

[2] D. E. Daniel and C. D. Shackelford, "Diffusion in Saturated Soil. I: Background,” Geotechnical Engineering, Vol. 117, No. 3, 1991, pp. 467-484.

[3] R. W. Gillham and J. A. Cherry, “Contaminant Transport by Ground Water in Non Indurated Deposits, in Recent Trends in Hydrogeology,” In: T. N. Narisimhan, Ed., Geological Society of America, 1982, pp. 31-62.

[4] Y. Acar and L. Haider, "Transport of Low-Concentration Contaminant in Saturated Earthen Barriers,” Geotechnical Engineering, Vol. 116, No. 7, 1990, pp. 1031-1052.

[5] R. K. Rowe, R. M. Quigley and R. J. Booker, "Clayey Barrier Systems for Waste Disposal Facilities,” E \& FN Spon Press, London, 1995.

[6] H. D. Sharma and S. P. Lewis, "Waste Containment Systems, Waste Stabilization and Landfills: Design and Evaluation,” John Wiley \& Sons Inc., New York, 1994.

[7] C. D. Shackelford, "Laboratory Diffusion Testing for Waste Disposal: A Review,” Journal of Contaminant Hydrology, Vol. 7, No. 3, 1991, pp. 177-217.

[8] F. S. Barone, E. K. Yanful, R. M. Quigley and R. K. Rowe, "Effect of Multiple Contaminant Migration on Diffusion and Adsorption of Some Domestic Waste Contaminants in a Natural Clayey Soil,” Canadian Geotechnical Journal,Vol. 26, 1988, pp. 189-198.

[9] J. J. Fried and M. A. Combarnous, "Dispersion in Porous Media,” In: Show, V. T. Ed., Advances in Hydroscience, Academic Press, New York, Vol. 7, 1971, pp. 169-282.

[10] A. Ogata and R. B. Banks, "A Solution of the Differential Equation of Longitudinal Dispersion in Porous Media,” US Geological Survey, No. 411-A, 1961, p. 7. 